Check for updates

Cite this: Phys. Chem. Chem. Phys.,

2021, 23, 4167

Received 28th November 2020 Accepted 2nd February 2021

DOI: $10.1039 / \mathrm{d} 0 \mathrm{cp} 06175 a$

rsc.li/pccp

\title{
High coordination number actinide-noble gas complexes; a computational study $\dagger$
}

\author{
Lin Yang, (D) Sophie Cooper (D) and Nikolas Kaltsoyannis (DD *
}

\begin{abstract}
The geometries, electronic structures and bonding of early actinide-noble gas complexes are studied computationally by density functional and wavefunction theory methods, and by ab initio molecular dynamics. $\mathrm{AcHe}_{18}{ }^{3+}$ is confirmed as being an 18 -coordinate system, with all of the $\mathrm{He}$ atoms accommodated in the primary coordination shell, and this record coordination number is reported for the first time for $\mathrm{Th}^{4+}$ and $\mathrm{Th}^{3+}$. For $\mathrm{Pa}$ and $\mathrm{U}$ in their group valences of 5 and 6 respectively, the largest number of coordinated He atoms is 17. For $\mathrm{AnHe}_{17}{ }^{q+}(\mathrm{An}=\mathrm{Ac}, q=3$; $\mathrm{An}=\mathrm{Th}, q=4 ; \mathrm{An}=\mathrm{Pa}, q=5$; $A n=U, q=6)$, the average An-He binding energy increases significantly across the series, and correlates linearly with the extent of $\mathrm{He} \rightarrow \mathrm{An}^{q+}$ charge transfer. The interatomic exchange-correlation term $V_{\mathrm{xc}}$ obtained from the interacting quantum atoms approach correlates linearly with the An-He quantum theory of atoms-in-molecules delocalization index, both indicating that covalency increases from $\mathrm{AcHe}_{17}{ }^{3+}$ to $\mathrm{UHe}_{17}{ }^{6+}$. The correlation energy in $\mathrm{AnHe}_{16}{ }^{3+}$ obtained from MP2 calculations decreases in the order $\mathrm{Pa}>\mathrm{Th}>\mathrm{U}>\mathrm{Ac}$, the same trend found in $V_{\mathrm{xc}}$. The most stable complexes of $\mathrm{Ac}^{3+}$ with the heavier noble gases $\mathrm{Ar}-\mathrm{Xe}$ are 12 coordinate, best described as $\mathrm{Ng}_{12}$ cages encapsulating an $\mathrm{Ac}^{3+}$ ion. There is enhanced $\mathrm{Ng} \rightarrow \mathrm{Ac}^{3+}$ charge transfer as the $\mathrm{Ng}$ gets heavier, and $\mathrm{Ac}-\mathrm{Ng}$ covalency increases.
\end{abstract}

\section{Introduction}

The noble gas $(\mathrm{Ng})$ elements, with their completely filled principal quantum shells, were considered unreactive for a long time. However, the 1962 report of the first stable $\mathrm{Ng}$ compound, $\mathrm{Xe}^{+}\left[\mathrm{PtF}_{6}\right]^{-}$disproved that view, ${ }^{1}$ and a new field of chemistry was opened. After that, many scientists devoted themselves to noble gas chemistry, and various new $\mathrm{Ng}$ compounds were reported from both experimental and theoretical studies. $^{2-5}$ Among them, actinide-Ng complexes, $\mathrm{CUO}(\mathrm{Ar})_{4-n}(\mathrm{Ng})_{n}$ $(\mathrm{Ng}=\mathrm{Kr}-\mathrm{Xe}, n=1-4)$, were first reported by Andrews et al. in $2002 .{ }^{6}$ During the synthesis of CUO by laser ablation of U and CO in Ng matrices, it was found that the vibrational spectrum of CUO in an Ar matrix was different from that in a Ne matrix, with the spectral shift from Ne to Ar being much larger than the normal "matrix shift". Combined with density functional theory (DFT) calculations, Andrews et al. assigned the spectrum in Ar to triplet CUO, but to singlet CUO in Ne. Such matrix-induced ground-state reversal suggested direct $\mathrm{Ar}-\mathrm{U}$ bonding, and $\mathrm{U}-\mathrm{Ng}$ bonds were also found in $\mathrm{Kr}$ and Xe. The interaction between $\mathrm{U}$ and $\mathrm{Ng}$ was attributed to the donation of $\mathrm{Ng}$ lone pair electrons into vacant

Department of Chemistry, School of Natural Sciences, The University of Manchester, Oxford Road, Manchester M13 9PL, UK.

E-mail: nikolas.kaltsoyannis@manchester.ac.uk

† Electronic supplementary information (ESI) available. See DOI: 10.1039/ d0cp06175a orbitals of $\mathrm{U}$, suggesting that positively charged actinide compounds such as $\mathrm{UO}_{2}{ }^{2+}$ would have stronger interaction with $\mathrm{Ng}$ elements, and the U-Ng complexes $\left[\mathrm{UO}_{2}(\mathrm{Ne})_{6}\right]^{+},\left[\mathrm{UO}_{2}(\mathrm{Ng})_{5}\right]^{+}$ $(\mathrm{Ng}=\mathrm{Ar}-\mathrm{Xe})$ and $\mathrm{UO}_{2}(\mathrm{Ng})_{4}(\mathrm{Ng}=\mathrm{Ne}, \mathrm{Ar})$ were indeed subsequently reported. ${ }^{7,8}$ The larger average $\mathrm{U}-\mathrm{Ng}$ binding energy in $\left[\mathrm{UO}_{2}(\mathrm{Ng})_{5}\right]^{+}$vs. $\mathrm{UO}_{2}(\mathrm{Ng})_{4}$ and $\mathrm{CUO}(\mathrm{Ng})_{4}\left(\right.$ e.g. $23.6 \mathrm{~kJ} \mathrm{~mol}^{-1}$, $14.6 \mathrm{~kJ} \mathrm{~mol}^{-1}$ and $16.2 \mathrm{~kJ} \mathrm{~mol}^{-1}$ respectively for $\mathrm{Ng}=\mathrm{Ar}$ ) supports the influence of charge on U-Ng interaction strength, also found in $\operatorname{AuXe}_{n}{ }^{q+2,9}$

Actinide- $\mathrm{Ng}$ (especially $\mathrm{He}$ ) complexes are candidate molecules for achieving high coordination numbers. Coordination number (CN), originally defined as the total number of neighboring atoms directly bonded to the central atom in a molecule or ion, is a fundamental concept in coordination chemistry, and the experimental and theoretical search for compounds with high CN has a long history. ${ }^{10-13}$ Hermann et al. predicted the existence of $\mathrm{PbHe}_{15}{ }^{2+}$ with a CN of 15 by DFT calculation, ${ }^{14}$ and that even higher CN systems may be achievable in charged actinide-He interactions. Motivated by this work, our group ${ }^{15}$ theoretically studied actinide ions coordinated by $\mathrm{He}$ atoms and reported 17-coordinated $\mathrm{AcHe}_{17}{ }^{3+}, \mathrm{PaHe}_{17}{ }^{4+}$ and $\mathrm{ThHe}_{17}{ }^{4+}$ complexes, a step forward as for several years the highest known $\mathrm{CN}$ was 16. ${ }^{11-13} \mathrm{UHe}_{n}{ }^{q+}(q=2-6)$ and $\mathrm{PaHe}_{n}{ }^{5+}$ were also studied, but no stable structures were found with $n>15$. However, a year later, $\mathrm{AcHe}_{18}{ }^{3+}$ was reported by Ozama et al., using coupled cluster theory and path integral molecular dynamics (PIMD). ${ }^{16}$ According to their work, $18 \mathrm{He}$ atoms can be accommodated in the first 
coordination shell, in a highly symmetrical $D_{4 \mathrm{~d}}$ structure, the increase in $\mathrm{CN}$ from our work potentially being due to omission of basis set superposition error (BSSE) in our $\operatorname{CCSD}(\mathrm{T})$ calculations. Although $\mathrm{CN}$ higher than 18 has recently been reported for $\mathrm{M}\left(\mathrm{H}_{2}\right)_{12}{ }^{n+}(\mathrm{M}=\mathrm{Ac} \text {, Th, Pa, U, La, } n=3,4)^{17}$ and $\mathrm{An}(\mathrm{BH})_{24}(\mathrm{An}=\mathrm{Th}-$ $\mathrm{Cm}),{ }^{18}$ genuine $\mathrm{CNs}$ of 24 are debatable given the strong $\mathrm{H}-\mathrm{H}$ interaction in $\mathrm{M}\left(\mathrm{H}_{2}\right)_{12}{ }^{n+}$ and lack of direct evidence for true $24 \mathrm{M}-\mathrm{B}$ bonds in $\mathrm{An}(\mathrm{BH})_{24}$. High coordination number is also observed in metal cluster-based compounds. $\mathrm{M}(\mathrm{EH})_{12}(\mathrm{M}=\mathrm{Cr}$, $\mathrm{Mo}, \mathrm{W} ; \mathrm{E}=\mathrm{Zn}, \mathrm{Cd}, \mathrm{Hg})^{19}$ possess $12 \mathrm{M}$-ER bond paths which are characterized as 6 three-centre two-electron bonds by quantum theory of atoms-in-molecules (QTAIM) and MO analysis. Weak peripheral E-E bonding is also observed with lower bond order than the $\mathrm{M}-\mathrm{E}$ bonds. By contrast, $\left[\mathrm{Pt} @ \mathrm{~Pb}_{12}\right]^{2-},{ }^{20,21}$ which has similar geometry, is stabilized by strong interactions in the $\mathrm{Pb}$ icosahedron.

In this contribution, we study $\mathrm{AnHe}_{n}{ }^{q^{+}}$(An = Ac-U) using wavefunction theory, DFT and $a b$ initio molecular dynamics (AIMD) calculations, and probe the nature of the An-He interaction. The latter is investigated via the QTAIM, interacting quantum atoms (IQA) and natural population analysis (NPA) methods. We also extend the helium work to the heavier $\mathrm{Ng}$ elements neon, argon, krypton, and xenon, systemically investigating the nature of the $\mathrm{An}^{q^{+}}-\mathrm{Ng}$ interaction, including the influence of $\mathrm{Ng}$ polarizability.

\section{Computational details}

All the geometrical structures, binding energies and thermodynamic stabilities of $\mathrm{AnNg}_{n}{ }^{q+}$ complexes were studied by dispersioncorrected density functional theory methods (DFT-D3), ${ }^{22}$ as implemented in TURBOMOLE 7.3. ${ }^{23}$ Effective core potentials (ECPs) with 60 core electrons were used for the actinide elements along with the def-TZVPP valence basis sets, ${ }^{24-26}$ and the aug-cc-pV5Z basis set $^{27}$ was used for He. Stuttgart RLC basis sets and ECPs with 2, 10, 28 , and 46 core electrons respectively were used for $\mathrm{Ne}, \mathrm{Ar}, \mathrm{Kr}$, and $\mathrm{Xe}^{28,29}$ To ensure valid comparisons with the He results, both the aug-cc-pV5Z and Stuttgart RLC ECP basis sets were used for benchmark $\mathrm{AcNe}_{n}{ }^{3+}$ calculations (Table S1, ESI $\dagger$ ). The average $\mathrm{Ac}^{3+}-\mathrm{Ne}$ distance and distance range obtained, as well as the binding energies, are close, suggesting that comparisons may indeed be justifiably made between the He and heavier $\mathrm{Ng}$ results, despite the difference in $\mathrm{Ng}$ basis sets employed. Harmonic vibrational frequency analysis ${ }^{30}$ was conducted for all optimized structures to ensure that they are true minimum structures.

To benchmark the density functional selection, $\operatorname{CCSD}(\mathrm{T})^{31}$ calculations were conducted in MOLPRO $2019^{32}$ using the 60 electron ECP along with associated ECP60MWB_SEG valence basis set for An (Ac, U) ${ }^{24-26}$ and aug-cc-pV5Z basis set for He. ${ }^{27}$ $\mathrm{HF}^{33}$ and $\mathrm{MP}^{34}$ calculations were performed in Gaussian $16^{35}$ with the same basis sets as used for the $\operatorname{CCSD}(\mathrm{T})$ calculations. BSSE corrections were evaluated by the counterpoise correction method. $^{36}$

QTAIM and IQA ${ }^{37}$ calculations were conducted using the AIMAll software. ${ }^{38}$ The input files for the IQA calculations were generated from DFT calculations based on the B3LYP-D3 density functional ${ }^{39}$ because the BHLYP-D3 density functional (which is used for our other production DFT calculations) is not currently supported for IQA analysis in AIMAll. The details for the IQA calculations were as reported in our previous work. ${ }^{40}$ Natural population analysis (NPA) was carried out using NBO $7.0^{41}$ to obtain the natural charges and electron configurations of the $\mathrm{AnNg}_{n}{ }^{q+}$ complexes.

To study the thermodynamic stability of the optimized $\operatorname{AnNg}_{n}{ }^{q+}$ structures, AIMD calculations were performed in TURBOMOLE, using the Nosé-Hoover thermostat. ${ }^{42}$ The time step was set to 1.21 fs and the total simulation time to $1.25 \mathrm{ps}$ for $\mathrm{Ac}^{3+}-\mathrm{Ng}$ compounds. For the $\mathrm{Th}^{4+}-\mathrm{He}$ complexes, longer simulation times were used, $2.47 \mathrm{ps}$ and $3.71 \mathrm{ps}$ for temperatures of $3 \mathrm{~K}$ and $10 \mathrm{~K}$ respectively. The simulations for $\mathrm{AcHe}_{18}{ }^{3+}$ and $\mathrm{ThHe}_{18}{ }^{4+}$ were conducted twice, yielding similar results. Hence, simulations for the $\mathrm{Ac}^{3+}-\mathrm{Ng}$ complexes were conducted only once.

\section{Results and discussion}

\subsection{Potential energy curves for $\mathrm{An}^{3+}-\mathrm{He}$}

As stated in the Introduction, Ozama et al. reported that BSSE has a significant influence on the $\mathrm{Ac}^{3+}-\mathrm{He}$ potential energy curve at the ECP60MWB/CCSD(T) level. ${ }^{16}$ To verify this, we began by studying BSSE, calculating the potential energy curve for the $\mathrm{Ac}^{3+}-\mathrm{He}$ interaction with $\operatorname{CCSD}(\mathrm{T})$, with and without BSSE correction. Both contracted and uncontracted valence basis sets were used for Ac. As shown in Fig. 1(a), the effect of BSSE depends on whether the Ac basis set is contracted or uncontracted. The contracted basis set without BSSE gives the deepest potential well of $35.13 \mathrm{~kJ} \mathrm{~mol}^{-1}$, close to the $34.98 \mathrm{~kJ} \mathrm{~mol}^{-1}$ and $35.0 \mathrm{~kJ} \mathrm{~mol}^{-1}$ calculated by Ozama et al. and by us, respectively. However, the potential well without BSSE but using the uncontracted basis set is much shallower, $22.68 \mathrm{~kJ} \mathrm{~mol}^{-1}$ at $2.61 \AA$. BSSE correction leads to a shallowing of the potential energy curve, to $21.93 \mathrm{~kJ} \mathrm{~mol}^{-1}$ and $22.18 \mathrm{~kJ} \mathrm{~mol}^{-1}$ for contracted and uncontracted basis set respectively, close to the value of $21.94 \mathrm{~kJ} \mathrm{~mol}^{-1}$ predicted by Ozama et al. This suggests that BSSE correction has a marked influence on $\operatorname{CCSD}(\mathrm{T})$ calculations using contracted basis sets, but that the impact on uncontracted basis set calculations is slight. BSSE at the DFT level was also studied, using the PBE-D3 functional as a representative example (Fig. S1, ESI $\dagger$ ). The results suggest that the effect is very small, with potential well depths of $27.40 \mathrm{~kJ} \mathrm{~mol}^{-1}$ and $27.46 \mathrm{~kJ} \mathrm{~mol}^{-1}$ with and without BSSE correction, respectively. On the basis of these results, we (i) use BSSE-corrected contracted basis set $\operatorname{CCSD}(\mathrm{T})$ data as a benchmark to determine the most appropriate density functional (contracted basis sets are used for DFT calculations in the TURBOMOLE software) and (ii) neglect BSSE corrections in our DFT calculations.

$\mathrm{Ac}^{3+}-\mathrm{He}$ potential energy curves were calculated by various density functionals; the results from PBE-D3 and BHLYP-D3 are shown in Fig. 1(b) with the other data being plotted in Fig. S2 (ESI $\dagger$ ). All functionals match reasonably well with BSSE-corrected $\operatorname{CCSD}(\mathrm{T})$, with hybrid functionals performing slightly better than GGA. Among the hybrids, the BHLYP curve is the best match for 


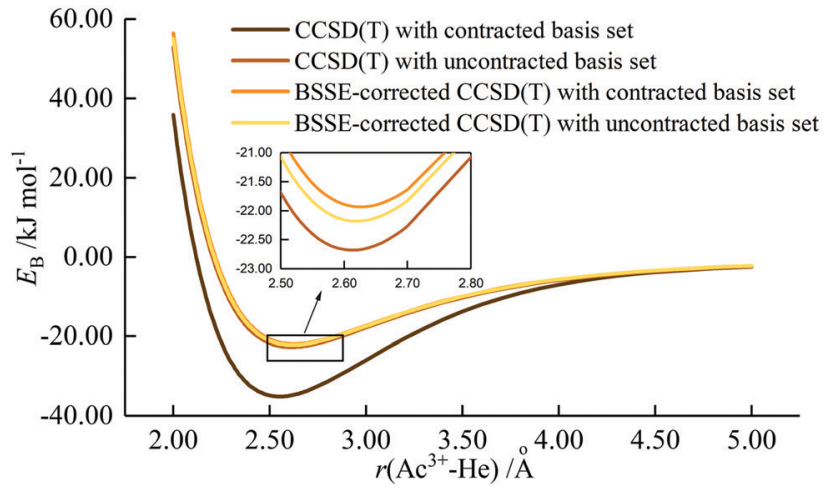

(a)

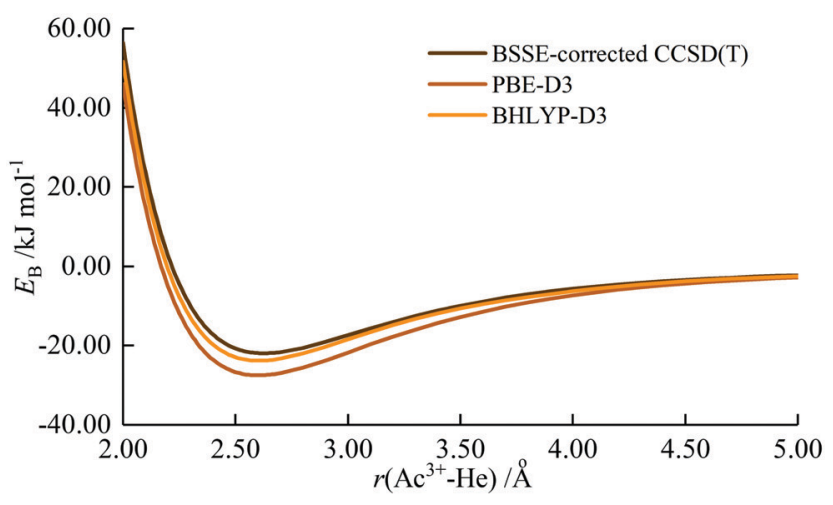

(b)

Fig. 1 Potential energy curves of $\mathrm{Ac}^{3+}-\mathrm{He}$ by (a) $\operatorname{CCSD}(\mathrm{T})$ calculation and (b) DFT calculation using PBE-D3 and BHLYP-D3 density functionals. ${ }^{39,43}$

the coupled cluster results, and hence BHLYP-D3 is used for geometry optimization and binding energy calculations of $\mathrm{AnNg}_{n}{ }^{q+}$. The only exception is $\mathrm{UHe}_{n}{ }^{3+}$, for which BHLYP-D3 gave a poor description of the $\mathrm{UHe}_{18}{ }^{3+}$ average binding energy (Fig. S3, ESI $\dagger$ ) and $\mathrm{U}^{3+}-$ He potential energy curve (Fig. S4, ESI $\dagger$ ). Fig. S4 (ESI $\dagger$ ) shows that the binding energies obtained from BHLYP-D3 are very large, leading to an extremely deep potential well which does not converge to 0 at large $\mathrm{U}^{3+}-\mathrm{He}$ distance. Further examination indicates that the total energy of $\mathrm{U}^{3+}$ obtained by BHLYP-D3 is appreciably less negative than from the other methods employed (Table S2, ESI $\dagger$ ), and also less negative than obtained from the same calculation performed in Gaussian 16, suggesting that TURBOMOLE does not converge to the correct ground state of $\mathrm{U}^{3+}$ with BHLYP. Given this observation and, as the curve from B3LYP-D3 matches better with that of $\operatorname{CCSD}(\mathrm{T})$, it is used for the study of $\mathrm{U}^{3+}-\mathrm{He}$ complexes.

\section{2. $\quad \mathrm{An}^{q+}-$ He complexes}

3.2.1 $\mathrm{Ac}^{3+}-\mathrm{He}$ complexes. Using the BHLYP-D3 functional, we were able to locate a $\mathrm{AcHe}_{18}{ }^{3+}$ true minimum structure. This is an increase in $\mathrm{CN}$ of one from our previous work, which employed the HFS functional, ${ }^{15}$ and located only $\mathrm{AcHe}_{17}{ }^{3+}$. The data in the previous section indicate that this difference arises from the omission of BSSE in our previous benchmarking $\operatorname{CCSD}(\mathrm{T})$ calculations, which generated an $\mathrm{Ac}^{3+}-\mathrm{He}$ well which

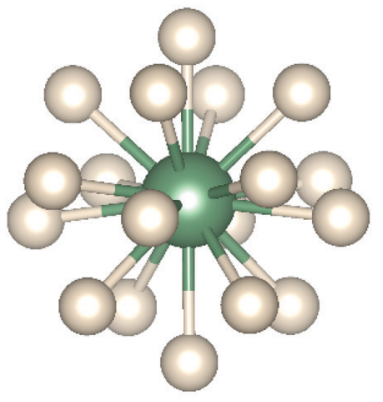

(a) $\mathrm{AcHe}_{18}{ }^{3+}$

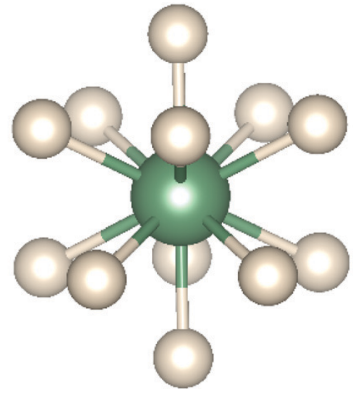

(b) $\mathrm{AcHe}_{12}{ }^{3+}$
Fig. 2 Optimized geometries of $\mathrm{AcHe}_{18}{ }^{3+}$ and $\mathrm{AcHe}_{12}{ }^{3+}$.

was too deep, and hence led to our using the HFS approach. The optimized structure of $\mathrm{AcHe}_{18}{ }^{3+}$ is shown in Fig. 2(a); it is close to a distorted tetrakis cuboctahedron and has $D_{4 \mathrm{~d}}$ symmetry, as reported by Ozama et al. ${ }^{16}$ Efforts to coordinate 19 and $20 \mathrm{He}$ atoms in the primary shell all failed.

The stability of $\mathrm{AcHe}_{18}{ }^{3+}$ was studied by AIMD at $10 \mathrm{~K}$, starting from the initial geometry shown in Fig. 2(a). The results are shown in Fig. 3; the lowest energy structure over the course of the simulation is the starting structure. Furthermore, the root mean square deviations of the He atoms from the initial structure are less than $0.15 \AA$, also indicating the stability of the $\mathrm{AcHe}_{18}{ }^{3+}$ structure, with only slight relaxation of the He atoms in the first coordination shell.

Geometrical parameters of $\mathrm{Ac}^{3+}-\mathrm{He}$ complexes from $n=1$ to 18 are listed in Table 1 . The average $\mathrm{Ac}^{3+}-\mathrm{He}$ distance increases by only $0.109 \AA$ from $n=1$ to 17 , with the bond distance range maximising at $0.039 \AA$ for the 16 -coordinate system. However, the bond distance range jumps to $0.108 \AA$ at $n=18$, with the average bond distance being $0.027 \AA$ longer than that at $n=17$, suggesting a crowded distribution of $\mathrm{He}$ atoms in $\mathrm{AcHe}_{18}{ }^{3+}$. However, the range of $0.108 \AA$ is still small enough to assign all $18 \mathrm{He}$ atoms to the primary coordination shell. That we find bond critical points (BCPs) between $\mathrm{Ac}^{3+}$ and all $18 \mathrm{He}$ atoms also supports this conclusion. Note also the very small bond length range for $n=12$ (Fig. 2(b)), $0.001 \AA$, rising to $0.026 \AA$ at $n=13$, due to disruption of the stable $\mathrm{AcHe}_{12}{ }^{3+}$ icosahedral structure. The average Ac-He distance of $\mathrm{AcHe}_{17}{ }^{3+}$ is $2.719 \AA$,

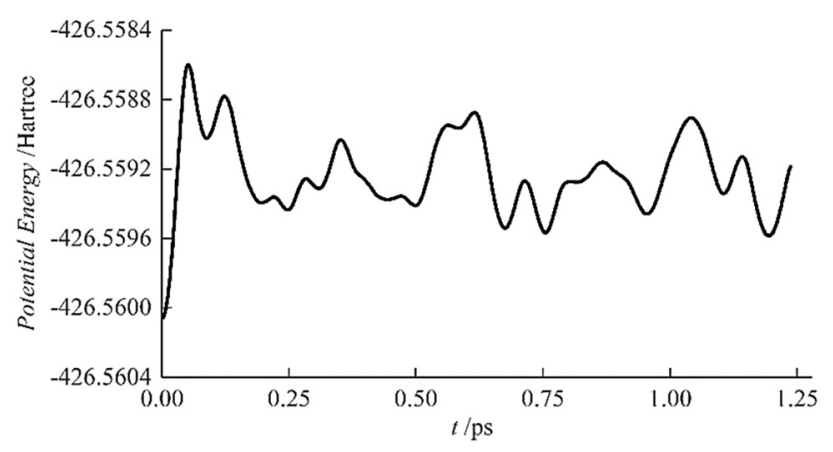

Fig. 3 Evolution of $\mathrm{AcHe}_{18}{ }^{3+}$ potential energy with time at $10 \mathrm{~K}$. 
Table 1 Average $\mathrm{Ac}^{3+}-\mathrm{He}$ distance $\left(r_{\mathrm{av}}\right)$ and distance range $(\Delta r)$ in $\mathrm{AcHe}_{n}{ }^{3+}(n=1-18)$

\begin{tabular}{llllll}
\hline$n$ & $r_{\mathrm{av}} / \AA$ & $\Delta r / \AA$ & $n$ & $r_{\mathrm{av}} / \AA$ & $\Delta r / \AA$ \\
\hline 1 & 2.610 & - & 10 & 2.638 & 0.016 \\
2 & 2.606 & 0.001 & 11 & 2.642 & 0.013 \\
3 & 2.611 & 0.005 & 12 & 2.644 & 0.001 \\
4 & 2.613 & 0.006 & 13 & 2.660 & 0.026 \\
5 & 2.620 & 0.011 & 14 & 2.671 & 0.018 \\
6 & 2.628 & 0.012 & 15 & 2.683 & 0.037 \\
7 & 2.631 & 0.013 & 16 & 2.701 & 0.039 \\
8 & 2.635 & 0.005 & 17 & 2.719 & 0.037 \\
9 & 2.638 & 0.011 & 18 & 2.746 & 0.108
\end{tabular}

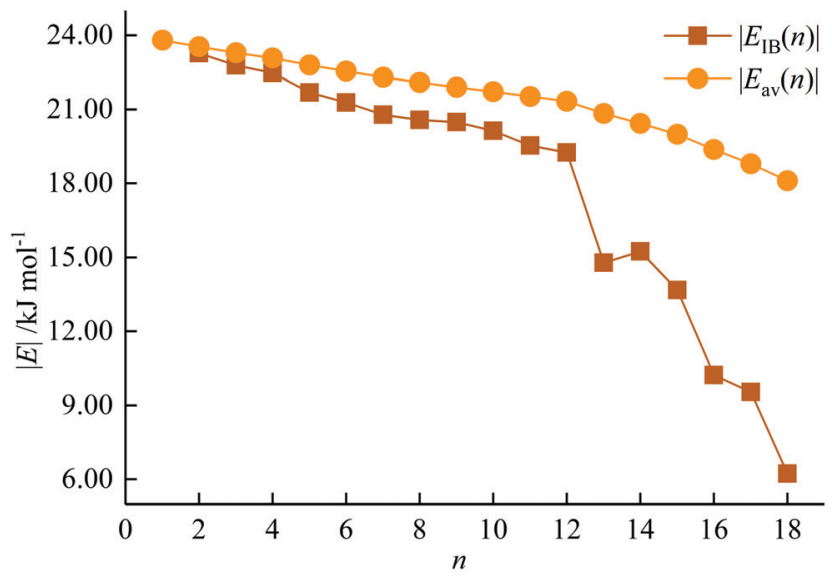

Fig. 4 Incremental $\left|E_{\mathrm{IB}}(n)\right|$ and average $\left|E_{\mathrm{av}}(n)\right|$ binding energies of $\mathrm{AcHe}_{n}{ }^{3+}(n=1-18)$.

larger than the $2.671 \AA$ that we reported before, ${ }^{15}$ consistent with the smaller revised $\mathrm{Ac}^{3+}-\mathrm{He}$ well depth.

The incremental $\left|E_{\mathrm{IB}}(n)\right|$ and average $\left|E_{\mathrm{av}}(n)\right|$ binding energies of $\mathrm{AcHe}_{n}{ }^{3+}(n=1-18)$ are plotted in Fig. $4 .\left|E_{\mathrm{IB}}(n)\right|$ is defined as the difference between the total energy of $\mathrm{AcHe}_{n}{ }^{3+}$ and the sum of the total energy of $\mathrm{AcHe}_{n-1}{ }^{3+}$ and $\mathrm{He}$, and represents the energy gain for each He atom attachment. $E_{\mathrm{av}}(n)$ is calculated by equation

$$
E_{\text {av }}(n)=\left(E(n)-E\left(\mathrm{Ac}^{3+}\right)-n \times E(\mathrm{He})\right) / n
$$

in which $E(n), E\left(\mathrm{Ac}^{3+}\right)$ and $E(\mathrm{He})$ are the total energy of $\mathrm{AcHe}_{n}{ }^{3+}$, $\mathrm{Ac}^{3+}$, and He. As shown in Fig. $4,\left|E_{\text {av }}(n)\right|$ decreases from $n=1$ to 18, which is as expected considering more $\mathrm{He}$ atoms are attached to the $\mathrm{Ac}^{3+}$ centre. $\left|E_{\mathrm{IB}}(n)\right|$ is similar to our PBE results in ref. 15, while smaller than the HFS result. It decreases steadily from $n=1$ to 12 , and then suddenly drops at $n=13$ before slightly increasing at 14 . The energy change from $n=12$ to 13 is consistent with the trend in $\mathrm{Ac}^{3+}-\mathrm{He}$ distance range, and the increase at $n=14$ is due to the establishment of a new stable structure as reported by Hermann and us. ${ }^{14,15}$ It is worth noting that the $\left|E_{\mathrm{IB}}(n)\right|$ at $n=18$ is only $6.24 \mathrm{~kJ} \mathrm{~mol}^{-1}$ which, together with the large Ac-He distance range of $\mathrm{AcHe}_{18}{ }^{3+}$, explains the failure to coordinate more than $18 \mathrm{He}$ atoms.

3.2.2 $\mathrm{Th}^{q+}-\mathrm{He}(q=3,4)$ complexes. The search for the highest $\mathrm{CN}$ of charged actinide- $\mathrm{Ng}$ complexes was extended to other

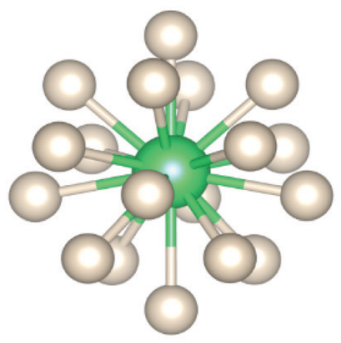

(a) $\mathrm{ThHe}_{18}{ }^{4+}$

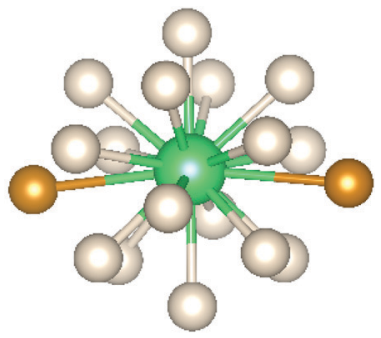

(b) $\mathrm{ThHe}_{18}{ }^{3+}$
Fig. 5 Optimized (a) $\mathrm{ThHe}_{18}{ }^{4+}$ and (b) $\mathrm{ThHe}_{18}{ }^{3+}$ geometries. The furthest two He atoms in the latter are highlighted in orange in (b).

Table 2 Geometrical parameters and average binding energies of $\mathrm{AnHe}_{n}{ }^{q+}$ in their highest $\mathrm{CN}$ structure

\begin{tabular}{lllc}
\hline & $r_{\text {av }} / \AA$ & $\Delta r / \AA$ & $\mid E_{\text {av }} / / \mathrm{kJ} \mathrm{mol}^{-1}$ \\
\hline $\mathrm{ThHe}_{18}{ }^{4+}$ & 2.541 & 0.151 & 42.001 \\
$\mathrm{ThHe}_{18}{ }^{3+}$ & 2.729 & 0.538 & 19.452 \\
$\mathrm{PaHe}_{17}{ }^{5+}$ & 2.360 & 0.053 & 90.604 \\
$\mathrm{PaHe}_{16}{ }^{3+}$ & 2.623 & 0.213 & 22.257 \\
$\mathrm{UHe}_{17}{ }^{6+}$ & 2.296 & 0.082 & 179.917 \\
$\mathrm{UHe}_{16}{ }^{3+}$ & 2.623 & 0.083 & 22.908
\end{tabular}

early actinide elements from Th to U. Both their group valence and trivalent oxidation states were considered. The 18-coordinated structure was also located for $\mathrm{ThHe}_{18}{ }^{q+}(q=3,4)$ with the geometries shown in Fig. 5 and Table 2. The geometry and symmetry of $\mathrm{ThHe}_{18}{ }^{4+}$ are similar to $\mathrm{AcHe}_{18}{ }^{3+}$ with a smaller Th-He distance $(2.541 \AA)$, while the average $\mathrm{Th}^{4+}-\mathrm{He}$ binding energy is $42.001 \mathrm{~kJ} \mathrm{~mol}^{-1}$, more than twice that of $\mathrm{Ac}^{3+}-\mathrm{He}$, likely due to the increased charge on $\mathrm{Th}^{4+} v s$. $\mathrm{Ac}^{3+}$.

To study the thermodynamic stability of $\mathrm{ThHe}_{18}{ }^{4+}$, AIMD calculations were conducted at $3 \mathrm{~K}$ and $10 \mathrm{~K}$. As shown in Fig. 6 , $\mathrm{ThHe}_{18}{ }^{4+}$ remains as the minimum potential energy structure at $3 \mathrm{~K}$. However, as the temperature is increased to $10 \mathrm{~K}$, the minimum potential energy structure changes to $\mathrm{ThHe}_{17}{ }^{4+}$, with the 18th He atom located in the second shell, i.e. the system is better represented as $\mathrm{ThHe}_{17+1}{ }^{4+}$. The Th-He distance range in the $\mathrm{ThHe}_{17}{ }^{4+}$ part is quite small $(0.040 \AA)$, and the distance difference between the two shells is $1.213 \AA$. Compared with $\mathrm{AcHe}_{18}{ }^{3+}$, the primary coordination shell of $\mathrm{ThHe}_{18}{ }^{4+}$ is more crowded, which leads to a reduction in the $\mathrm{CN}$ at higher temperature.

Although a stable $\mathrm{ThHe}_{18}{ }^{3+}$ structure was obtained, the range of $\mathrm{Th}^{3+}-\mathrm{He}$ distances is quite large (2.645-3.183 $\AA$ ). As shown in Fig. 5(b), there are two He atoms, highlighted in orange, with an average $\mathrm{Th}^{3+}-\mathrm{He}$ distance of $3.178 \AA$, farther out than the other $16 \mathrm{He}$ atoms (average $\mathrm{Th}^{3+}-\mathrm{He}$ distance $=$ $2.673 \AA$ A), making the CN 18 description debatable. However, QTAIM analysis shows BCPs between $\mathrm{Th}^{3+}$ and all $18 \mathrm{He}$ atoms (Fig. 7). The presence of a BCP can be considered as the indicator of a chemical bond. The average electron density at the BCPs between $\mathrm{Th}^{3+}$ and the two more distant He atoms is only 0.005 a.u., while the value is $0.013-0.015$ a.u. between $\mathrm{Th}^{3+}$ 


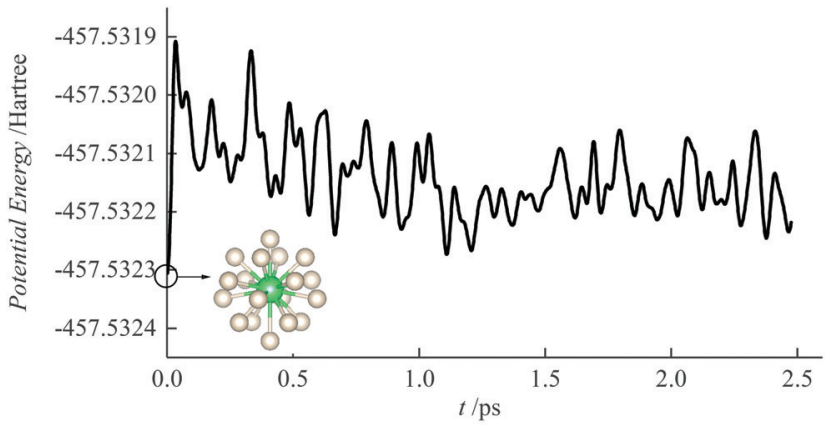

(a) Evolution of $\mathrm{ThHe}_{18}{ }^{4+}$ potential energy with time at $3 \mathrm{~K}$

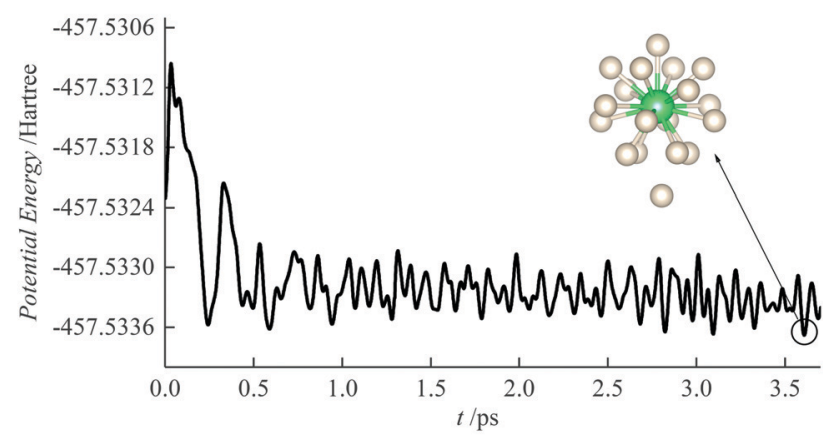

(b) Evolution of $\mathrm{ThHe}_{18}{ }^{4+}$ potential energy with time at $10 \mathrm{~K}$

Fig. 6 Evolution of $\mathrm{ThHe}_{18}{ }^{4+}$ potential energy by AIMD at (a) $3 \mathrm{~K}$ and (b) $10 \mathrm{~K}$. The initial structures are as shown in Fig. 5(a).

and the other $16 \mathrm{He}$ atoms. Therefore, we conclude that $\mathrm{ThHe}_{18}{ }^{3+}$ is genuinely 18-coordinated, although two of the bonds are extremely weak. Note that the average $\mathrm{Th}^{3+}-\mathrm{He}$ binding energy (19.452 $\mathrm{kJ} \mathrm{mol}^{-1}$ ) is slightly larger than the $18.098 \mathrm{~kJ} \mathrm{~mol}^{-1}$ of $\mathrm{Ac}^{3+}-\mathrm{He}$, but significantly less than that of $\mathrm{Th}^{4+}-\mathrm{He}$.

To further understand the actinide- $\mathrm{Ng}$ interaction within these highly coordinated complexes, QTAIM and NPA analysis for $\mathrm{ThHe}_{18}{ }^{q+}(q=3,4)$ were conducted, and the results are

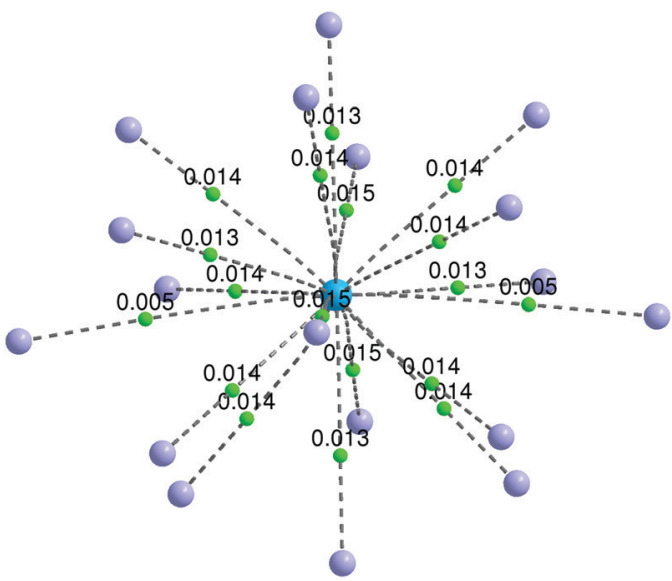

Fig. 7 Bond paths (dashed lines) and bond critical points (green dots) of $\mathrm{ThHe}_{18}{ }^{3+}$. The electron densities (a.u.) at the BCPs are displayed. He = purple spheres, $\mathrm{Th}=$ blue sphere. presented in Table 3. The data for $\mathrm{AcHe}_{18}{ }^{3+}$ are also given. Different from orbital-based analysis, QTAIM is based on the topology of the electron density. ${ }^{44}$ BCP properties such as the electron density $\left(\rho_{\mathrm{BCP}}\right)$, Laplacian of the electron density $\left(\nabla^{2} \rho_{\mathrm{BCP}}\right)$, the ratio of kinetic and potential energy densities $\left(-G_{\mathrm{BCP}} / V_{\mathrm{BCP}}\right)$, and the energy density $\left(H_{\mathrm{BCP}}\right)$ are all useful descriptors of chemical bonds. A general rule is that $\rho_{\mathrm{BCP}}>$ 0.2 a.u. and $H_{\mathrm{BCP}}<0$ are features of covalent interaction, while $\rho_{\text {BCP }}<0.1$ a.u. represents closed-shell interactions (ionic bonding, hydrogen bonding, van der Waals bonding). ${ }^{45} \mathrm{How}^{-}$ ever, for chemical bonds involving actinides, $\rho_{\mathrm{BCP}}$ is rarely larger than 0.2 and usually less than 0.1 a.u. $\nabla^{2} \rho_{\mathrm{BCP}}$ describes whether the electron density is concentrated $\left(\nabla^{2} \rho_{\mathrm{BCP}}<0\right)$ or depleted $\left(\nabla^{2} \rho_{\mathrm{BCP}}>0\right)$ at the BCP. For highly polarized bonds, positive $\nabla^{2} \rho_{\mathrm{BCP}}$ is possible. For BCPs with positive $\nabla^{2} \rho_{\mathrm{BCP}}$, $-G_{\mathrm{BCP}} / V_{\mathrm{BCP}}$ between 0.5 and 1 is a feature of covalent character, while $-G_{\mathrm{BCP}} / V_{\mathrm{BCP}}>1$ is considered to indicate non-covalent interaction. ${ }^{40}$ Moreover, the delocalization indices $(\delta)$, which represent the number of electrons shared between two atomic basis, is a widely used measure of bond order, and also a good indicator of covalence.

The QTAIM atomic charges in Table 3 indicate that the overall $q+$ charge partially redistributes between An and He due to electron transfer from the He atoms to the An centres. That said, the An QTAIM charges are close to the formal oxidation state in all cases, and the He charges are small. These charges indicate closed-shell bonding in $\mathrm{Th}^{q+}-\mathrm{He}$ and $\mathrm{Ac}^{3+}-\mathrm{He}$; this has been previously characterized as a charge-induced dipole interaction. ${ }^{15}$ The BCP data and small $\delta$ values further confirm this. Although the An/He charges calculated by NPA are not as disparate as those from the QTAIM, they are also suggestive of ionic bonding. Charge transfer, as well as $\rho_{\mathrm{BCP}}$ and $\delta$, for $\mathrm{ThHe}_{18}{ }^{4+}$ are larger than for $\mathrm{ThHe}_{18}{ }^{3+}$ and $\mathrm{AcHe}_{18}{ }^{3+}$ (which are similar to one another) consistent with the average $\mathrm{An}^{q+}-\mathrm{He}$ binding energy being mainly determined by the charge on the metal centre, as noted above.

3.2.3 $\mathrm{An}^{q+}-\mathrm{He}(\mathrm{An}=\mathrm{Pa}, q=3,5$; $\mathrm{An}=\mathrm{U}, q=3,6)$ complexes. The highest $\mathrm{CN}$ obtained for $\mathrm{Pa}^{5+}-\mathrm{He}$ and $\mathrm{U}^{6+}-\mathrm{He}$ complexes is 17, and 16 for $\mathrm{Pa}^{3+}-\mathrm{He}$ and $\mathrm{U}^{3+}-\mathrm{He}$ complexes. It is not unexpected to find lower $\mathrm{CN}$ of $\mathrm{Pa}^{q+}$ and $\mathrm{U}^{q+}$ than $\mathrm{Th}^{q+}$ and $\mathrm{Ac}^{3+}$, given the smaller ionic radii of the former and the increased $\mathrm{An}^{q+}-\mathrm{He}$ distance range from $\mathrm{Ac}^{3+}$ to $\mathrm{Th}^{q^{+}}$. The CNs of 17 and 16 reported here are higher than the 15 suggested in our previous work for $\mathrm{Pa}^{5+}-\mathrm{He}$ and $\mathrm{U}^{q+}-\mathrm{He}(q=2-6),{ }^{15}$ as well as in other reported actinide complexes. ${ }^{46,47}$

18-Coordinated structures were also located for $\mathrm{PaHe}_{18}{ }^{3+}$ and $\mathrm{UHe}_{18}{ }^{3+}$, but were found to have imaginary frequencies. To obtain true minima, the $\mathrm{PaHe}_{18}{ }^{3+}$ and $\mathrm{UHe}_{18}{ }^{3+}$ structures were distorted along the largest imaginary mode and re-optimized, resulting in lower energy $\mathrm{AnHe}_{16}{ }^{3+}(\mathrm{An}=\mathrm{Pa}, \mathrm{U})$ structures with the remaining two He atoms located in the second shell. The geometries of these complexes are given in Fig. 8 and Table 2 . $\mathrm{PaHe}_{17}{ }^{5+}$ and $\mathrm{UHe}_{17}{ }^{6+}$ have similar symmetry and geometry to one another, with the average $\mathrm{An}^{q+}$-He distances being $2.360 \AA$ and $2.296 \AA$, respectively. The average $\mathrm{Pa}^{5+}-\mathrm{He}$ and $\mathrm{U}^{6+}-\mathrm{He}$ binding energies are much larger than that of $\mathrm{Th}^{4+}-\mathrm{He}$, which 
Table 3 QTAIM metrics (a.u.) and NPA charges for optimized $\mathrm{AcHe}_{18}{ }^{3+}$ and $\mathrm{ThHe}_{18}{ }^{q+}(q=3,4)$

\begin{tabular}{|c|c|c|c|c|c|c|c|c|c|}
\hline & \multicolumn{4}{|c|}{ Atomic charge } & \multicolumn{4}{|c|}{ BCP properties } & \multirow[b]{2}{*}{$\delta$} \\
\hline & $q_{\mathrm{An}}$ & $q_{\mathrm{He}}$ & $q_{\mathrm{An}}$ & $q_{\mathrm{He}}$ & $\rho_{\mathrm{BCP}}$ & $\nabla^{2} \rho_{\mathrm{BCP}}$ & $-\left(G_{\mathrm{BCP}} / V_{\mathrm{BCP}}\right)$ & $H_{\mathrm{BCP}}$ & \\
\hline $\mathrm{ThHe}_{18}{ }^{3+}$ & 2.827 & 0.010 & 1.766 & 0.069 & 0.013 & 0.061 & 1.247 & 0.002 & 0.053 \\
\hline $\mathrm{ThHe}_{18}{ }^{4+}$ & 3.613 & 0.021 & 2.226 & 0.099 & 0.020 & 0.083 & 1.154 & 0.002 & 0.077 \\
\hline
\end{tabular}

we attribute in part to the reduced steric effect induced by the reduction in $\mathrm{CN}$, but primarily to the increased metal charge of $\mathrm{Pa}^{5+}$ and $\mathrm{U}^{6+}$, as found in the comparison of $\mathrm{ThHe}_{18}{ }^{4+}$ and $\mathrm{AcHe}_{18}{ }^{3+}$. For $\mathrm{PaHe}_{16}{ }^{3+}$ and $\mathrm{UHe}_{16}{ }^{3+}$, the average $\mathrm{An}^{3+}-\mathrm{He}$ distances are the same with the distance range of the latter being smaller. The average binding energy of $\mathrm{UHe}_{16}{ }^{3+}$ is slightly larger than that of $\mathrm{PaHe}_{16}{ }^{3+}$, but this increase is small compared with that from $\mathrm{PaHe}_{17}{ }^{5+}$ to $\mathrm{UHe}_{17}{ }^{6+}$, as found for $\mathrm{ThHe}_{18}{ }^{n+}$ complexes as noted above. This further indicates the significant influence of metal charge on $\mathrm{An}^{q+}-\mathrm{He}$ interaction.

3.2.4 The nature of the $\mathrm{An}^{q+}-\mathrm{He}$ interaction. In order to study the dependence of the nature of the $\mathrm{An}^{q+}-\mathrm{He}$ interaction on An and oxidation state, QTAIM, IQA, and NPA analyses were conducted on $\mathrm{AnHe}_{17}{ }^{q+}$ and $\mathrm{AnHe}_{16}{ }^{3+}(\mathrm{An}=\mathrm{Ac}-\mathrm{U})$, selected as they form families of closed-shell and trivalent $\mathrm{AnHe}_{n}{ }^{q^{+}}$ complexes, respectively.

$\mathrm{AnHe}_{17^{q+}}$. As shown in Table 4, the average An-He distance in $\mathrm{AnHe}_{17}{ }^{q+}$ decreases significantly from Ac to $\mathrm{U}$, while the average binding energy increases substantially. The atomic

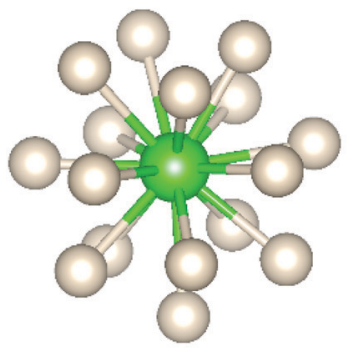

(a) $\mathrm{PaHe}_{16}{ }^{3+}$

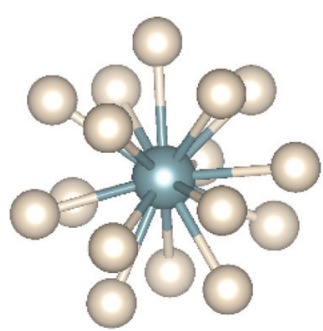

(c) $\mathrm{UHe}_{16}{ }^{3+}$

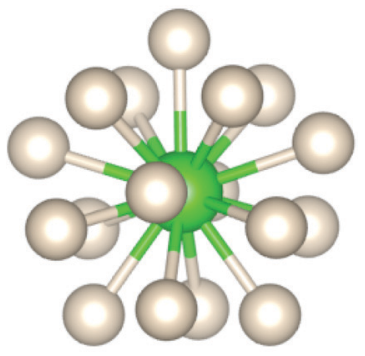

(b) $\mathrm{PaHe}_{17}{ }^{5+}$

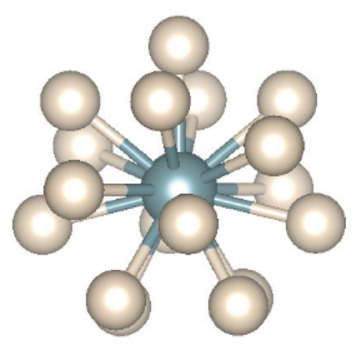

(d) $\mathrm{UHe}_{17}{ }^{6+}$
Fig. 8 Optimized $\mathrm{AnHe}_{n}{ }^{q+}(\mathrm{An}=\mathrm{Pa}, q=3,5 ; \mathrm{An}=\mathrm{U}, q=3,6)$ configurations. charges on the actinide ions deviate from their formal oxidation states, suggesting that part of the overall positive charge is acquired by the He atoms. This charge transfer increases across the series from Ac to U, with the partial charge on Ac(III) close to its formal oxidation state but increasingly less so from $\mathrm{Th}(\mathrm{Iv})$ to $\mathrm{U}(\mathrm{vI})$. The average binding energy correlates linearly with this charge transfer $\left(R^{2}=0.999\right)$. We noted above that the $\mathrm{Th}^{q+}-\mathrm{He}(q=3,4)$ and $\mathrm{Ac}^{3+}-\mathrm{He}$ interaction is primarily charge-induced dipole, with little charge transfer and small delocalization indices. This description is also suitable for the Pa-He interaction in $\mathrm{PaHe}_{17}{ }^{5+}$, given the small $\rho_{\mathrm{BCP}}$ value, positive $H_{\mathrm{BCP}}$, and $-G_{\mathrm{BCP}} / V_{\mathrm{BCP}}$ greater than 1. However, considering the charge loss of 1.73 for $\mathrm{U}(\mathrm{vr})$ and small negative $H_{\mathrm{BCP}}$, this description is arguably less appropriate for U-He, which shows more Lewis acid-base interaction characteristics. $-G_{\mathrm{BCP}} / V_{\mathrm{BCP}}$ between 0.5 and 1.0 further evidences this. Furthermore, $\rho_{\mathrm{BCP}}$ and $\delta$ rise from Ac to $\mathrm{U}$, suggesting increasing covalency.

The exchange-correlation energy $\left(V_{\mathrm{xc}}\right)$ between An and $\mathrm{He}$, obtained from IQA analysis, is also listed in Table 4. IQA is a real-space energy partitioning method based on topology theory, with good performance in quantifying chemical bonding, which has only recently begun to be employed in the $5 f$ series. ${ }^{40,48}$ According to the IQA approach, the interatomic energy $\left(V_{\text {int }}\right)$ can be decomposed into electrostatic $\left(V_{\text {Elec }}\right)$ and exchange-correlation terms $\left(V_{\mathrm{xc}}\right) .^{37}$ The former is composed of the nuclear-nuclear repulsive energy, electron-electron coulombic repulsion energy, and the electron-nuclear attraction energy. $V_{x c}$ is a good descriptor of the covalent contribution to the interatomic energy, and it can be seen from Table 4 that $V_{\mathrm{xc}}$ becomes more negative as the series is crossed. Considering that the more negative $V_{\mathrm{xc}}$, the higher the degree of covalency, IQA gives the same trend as the other QTAIM metrics, i.e. that covalency increases from Ac to U in this closed-shell family. As shown in Fig. 9(a), $V_{\mathrm{xc}}$ shows excellent correlation with $\delta\left(R^{2}=0.991\right)$, which is a more widely used indicator of covalency. This further suggests that the IQA method can be a useful tool in the study of covalency in the $5 \mathrm{f}$ series.

To further analyze the electronic structures of these complexes, the natural charges and natural electron configurations were explored using NPA, and are listed in Table 5, together with the Wiberg bond indices (WBIs). The trend in the NPA charges of $\mathrm{He}$ in $\mathrm{AnHe}_{17}{ }^{q+}$ is the same as that obtained from QTAIM but with more charge being acquired by $\mathrm{He}$, similar to the behaviour noted above, indicating less closed-shell interaction compared with QTAIM. Like $V_{\mathrm{xc}}$, WBI is very strongly correlated with $\delta\left(R^{2}=0.985\right)$. Given the charge transfer, it is unsurprising that the natural electron configurations show 
Table 4 Average $\mathrm{An}^{q+}-\mathrm{He}$ distance, $\mathrm{An}^{q+}-\mathrm{He}$ binding energies, QTAIM (a.u.) and IQA metrics for the optimized $\mathrm{AnHe}_{n}{ }^{q+}$ complexes

\begin{tabular}{|c|c|c|c|c|c|c|c|c|c|c|}
\hline & $r_{\mathrm{av}} / \AA$ & $E_{\mathrm{av}} / \mathrm{kJ} \mathrm{mol}^{-1}$ & $q_{\mathrm{An}}$ & $q_{\mathrm{He}}$ & $\rho_{\mathrm{BCP}}$ & $\nabla^{2} \rho_{\mathrm{BCP}}$ & $-\frac{G_{\mathrm{BCP}}}{V_{\mathrm{BCP}}}$ & $H_{\mathrm{BCP}}$ & $\delta$ & $V_{\mathrm{xc}} / \mathrm{kJ} \mathrm{mol}^{-1}$ \\
\hline $\mathrm{AcHe}_{17}{ }^{3+}$ & 2.719 & -18.796 & 2.802 & 0.009 & 0.013 & 0.058 & 1.263 & 0.002 & 0.053 & -27.543 \\
\hline $\mathrm{ThHe}_{17}{ }^{4+}$ & 2.511 & -44.121 & 3.604 & 0.023 & 0.022 & 0.090 & 1.138 & 0.002 & 0.085 & -48.296 \\
\hline $\mathrm{PaHe}_{17}{ }^{5+}$ & 2.360 & -90.604 & 4.144 & 0.050 & 0.033 & 0.118 & 1.023 & 0.001 & 0.139 & -83.375 \\
\hline $\mathrm{UHe}_{17}{ }^{6+}$ & 2.296 & -179.917 & 4.259 & 0.102 & 0.040 & 0.123 & 0.958 & -0.001 & 0.230 & -124.580 \\
\hline $\mathrm{AcHe}_{16}{ }^{3+}$ & 2.701 & -19.374 & 2.802 & 0.012 & 0.014 & 0.059 & 1.247 & 0.002 & 0.062 & -29.507 \\
\hline $\mathrm{ThHe}_{16}{ }^{3+}$ & 2.650 & -21.270 & 2.779 & 0.014 & 0.015 & 0.067 & 1.213 & 0.002 & 0.070 & -33.444 \\
\hline $\mathrm{PaHe}_{16}{ }^{3+}$ & 2.623 & -22.257 & 2.761 & 0.015 & 0.016 & 0.071 & 1.198 & 0.003 & 0.072 & -34.859 \\
\hline $\mathrm{UHe}_{16}{ }^{3+}$ & 2.623 & -22.908 & 2.754 & 0.015 & 0.015 & 0.069 & 1.198 & 0.002 & 0.069 & -33.302 \\
\hline
\end{tabular}

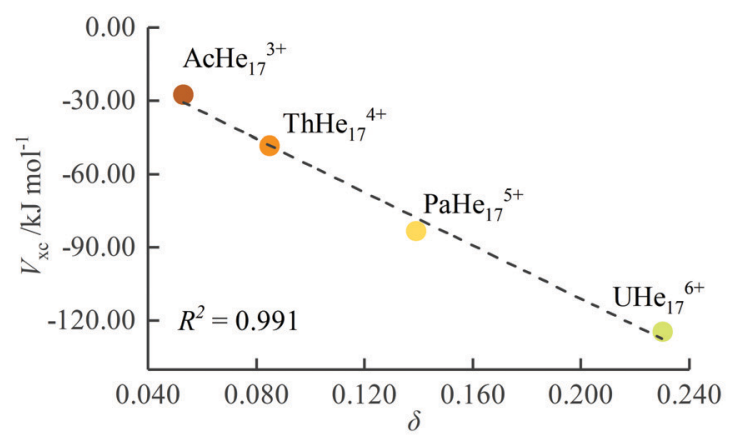

(a) $\mathrm{AnHe}_{17}{ }^{q+}$

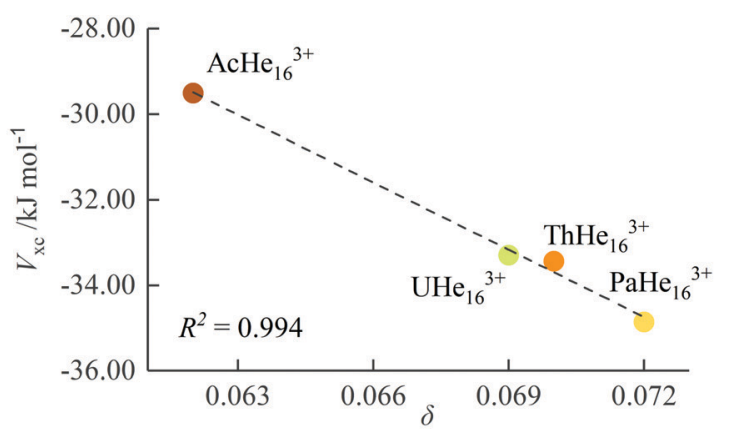

(b) $\mathrm{AnHe}_{16}{ }^{3+}$

Fig. 9 The correlation between $V_{x c}$ and $\delta$ for $\mathrm{AnHe}_{n}{ }^{q+}$.

significant deviation from the formal oxidation states, in which the valence orbitals are expected to be empty. The occupancies of all valence orbitals increase from $\mathrm{AcHe}_{17}{ }^{3+}$ to $\mathrm{UHe}_{17}{ }^{6+}$, although the details differ. For $\mathrm{AcHe}_{17}{ }^{3+}$, the electrons mainly occupy the $6 \mathrm{~d}$ orbitals, with the $5 \mathrm{f}$ occupancy being 0.08 . Although the $6 \mathrm{~d}$ populations are also larger than $5 \mathrm{f}$ for $\mathrm{ThHe}_{17}{ }^{4+}$ and $\mathrm{PaHe}_{17}{ }^{5+}$, the $5 \mathrm{f}$ increases significantly and, for $\mathrm{UHe}_{17}{ }^{6+}$, the occupation of $5 \mathrm{f}$ exceeds that of $6 \mathrm{~d}$. The increasing occupation of the $5 \mathrm{f}$ orbitals in part reflects their stabilization across the actinide series, as reported in previous theoretical work. ${ }^{49,50}$

Table 5 Wiberg bond index (WBI) of $\mathrm{An}^{q+}-\mathrm{He}$, natural charge, and natural electronic configuration of $\mathrm{An}^{q+}$ in $\mathrm{AnHe}_{17}{ }^{q+}$ and $\mathrm{AnHe}_{16}{ }^{3+}$. For the electronic configurations, the values listed are those above the formal populations (shown in parentheses). As the $7 p$ populations are negligible, they are not shown. Note that there are $0.22,0.29$, and 0.15 metal Rydberg electrons in $\mathrm{ThHe}_{16}{ }^{3+}, \mathrm{PaHe}_{16}{ }^{3+}$ and $\mathrm{UHe}_{16}{ }^{3+}$ respectively

\begin{tabular}{|c|c|c|c|c|c|c|}
\hline & \multirow[b]{2}{*}{ WBI } & \multirow[b]{2}{*}{$q_{\mathrm{An}}$} & \multirow[b]{2}{*}{$q_{\mathrm{He}}(\mathrm{av})$} & \multicolumn{3}{|c|}{ Natural electronic configuration } \\
\hline & & & & $7 \mathrm{~s}$ & $5 f$ & $6 \mathrm{~d}$ \\
\hline$\overline{\mathrm{AcHe}_{17}{ }^{3+}}$ & 0.054 & 2.251 & 0.044 & (0) 0.18 & (0) 0.08 & $\overline{(0)} 0.48$ \\
\hline $\mathrm{ThHe}_{17}{ }^{4+}$ & 0.119 & 2.338 & 0.098 & (0) 0.29 & 0.44 & (0) 0.92 \\
\hline $\mathrm{PaHe}_{17}{ }^{5+}$ & 0.187 & 2.292 & 0.159 & (0) 0.36 & (0) 1.02 & (0) 1.31 \\
\hline $\mathrm{UHe}_{17}{ }^{6+}$ & 0.286 & 1.789 & 0.248 & (0) 0.37 & (0) 2.23 & (0) 1.58 \\
\hline $\mathrm{AcHe}_{16}{ }^{3+}$ & 0.053 & 2.304 & 0.044 & (0) 0.17 & (0) 0.17 & (0) 0.45 \\
\hline $\mathrm{ThHe}_{16}{ }^{3+}$ & 0.138 & 1.827 & 0.073 & (0) 0.21 & (1) 0.10 & (0) 0.65 \\
\hline $\mathrm{PaHe}_{16}{ }^{3+}$ & 0.151 & 1.714 & 0.080 & (0) 0.22 & (2) 0.11 & (0) 0.67 \\
\hline $\mathrm{UHe}_{16}{ }^{3+}$ & 0.136 & 1.846 & 0.072 & (0) 0.21 & (3) 0.12 & (0) 0.67 \\
\hline
\end{tabular}

$\mathrm{AnHe}_{16}{ }^{3+}$. As discussed in Section 3.1, the BHLYP-D3 functional failed to convincingly describe $\mathrm{U}^{3+}$-based complexes, and hence we employed B3LYP-D3 for calculations on $\mathrm{UHe}_{16}{ }^{3+}$. To systematically study trivalent An-He, QTAIM and NBO analyses for $\mathrm{AnHe}_{16}{ }^{3+}(\mathrm{An}=\mathrm{Ac}-\mathrm{U})$ were all conducted from single-point calculations using B3LYP-D3, and the results are collected in Table 4 . The average An-He distance shortens across the early actinide series, following the An trivalent radius contraction; that $r(\mathrm{~Pa}-\mathrm{He})$ and $r(\mathrm{U}-\mathrm{He})$ are the same as one another is likely due to the very similar ionic radii of $\mathrm{Pa}^{3+}(1.04 \AA)$ and $\mathrm{U}^{3+}$ $(1.03 \AA)$. The average binding energy increases slightly from $\mathrm{AcHe}_{16}{ }^{3+}$ to $\mathrm{UHe}_{16}{ }^{3+}$, and the values for the Th, Pa and $\mathrm{U}$ systems are significantly smaller than in the corresponding $\mathrm{AnHe}_{17}{ }^{q+}$. Moreover, the energy difference between $\mathrm{AnHe}_{16}{ }^{3+}$ and the corresponding closed-shell $\mathrm{AnHe}_{17}{ }^{q+}$ rises from Ac to $\mathrm{U}$, further illustrating the strong influence of metal charge on the $\mathrm{An}^{q^{+}}-\mathrm{He}$ interaction.

Turning to the QTAIM metrics, the small values of $\rho_{\mathrm{BCP}}$ and $\delta$, and the positive $\nabla^{2} \rho_{\mathrm{BCP}}$ and $H_{\mathrm{BCP}}$, all indicate chargeinduced dipole interaction for all $\mathrm{AnHe}_{16}{ }^{3+}$ complexes. The charge difference between metal and $\mathrm{He}$ decreases slightly from Ac to $\mathrm{U}$, although this change is small compared with the closed-shell $\mathrm{AnHe}_{17}{ }^{q+}$ complexes. The BCP electron densities are very similar for all four complexes, with that for Ac-He being slightly smaller, similar to the charge transfer trend. $-G_{\mathrm{BCP}} / V_{\mathrm{BCP}}$ also suggests that the Ac system is the most ionic, as does $\delta$, from which the covalency trend is $\mathrm{Pa}>\mathrm{Th}>\mathrm{U}>$ Ac. $V_{\mathrm{xc}}$ indicates the same trend and once again shows excellent 
correlation with $\delta\left(R^{2}=0.994\right.$, Fig. 9(b)). Notably, the difference in $\delta$ and $V_{\mathrm{xc}}$ between the trivalent $\mathrm{AnHe}_{16}{ }^{3+}$ and group valent $\mathrm{AnHe}_{17}{ }^{q+}$ complexes increase very significantly from Ac to U, suggesting significantly greater covalency in the higher oxidation state systems. To place the QTAIM metrics for the An-He complexes in context, the values of $\rho_{\mathrm{BCP}}, \delta$, and $V_{\mathrm{xc}}$ as a function of the shortening and elongation of the An-He bond length are studied for $\mathrm{An}^{3+}-\mathrm{He}$ diatomic systems (Fig. S5, ESI $\dagger$ ).

The natural charge and WBI data (Table 5) show the same trend as the QTAIM and IQA metrics, and once again the correlation of WBI with $\delta$ is very strong $\left(R^{2}=0.978\right)$. As discussed above, the enhanced charge transfer predicted by NPA suggests less of a closed-shell interaction nature. The natural electronic configuration data show that the largest enhancement in all valence orbitals is in the $6 \mathrm{~d}$, indicating that the An 6d orbital is the principal acceptor of He electron density in $\mathrm{AnHe}_{16}{ }^{3+}$.

In order to study the effect of correlation on the $\mathrm{An}^{3+}-\mathrm{He}$ bonding, HF and MP2 calculations were performed at the DFT optimized geometries, and the results are plotted in Fig. S6 (ESI $\dagger$ ). Although the average binding energies are smaller at the HF level than the DFT, the trend as function of actinide is similar, with a slight increase from Ac to U. At the MP2 level, the binding energies are extremely close to the DFT values for Th to U, but that for $\mathrm{AcHe}_{16}{ }^{3+}$ is rather larger than from DFT. As with the $\operatorname{CCSD}(\mathrm{T})$ data presented in Section 3.1, correction for BSSE significantly reduces the depth of the potential energy curve of $\mathrm{Ac}^{3+}-\mathrm{He}$ at the MP2 level, bringing it close to the DFT value and resulting in a trend similar to that from DFT and HF. BSSE has less of an effect on the MP2 data for the later members of our target series. The correlation energy, obtained as the difference between the MP2 and HF results, is largest for $\mathrm{Pa}\left(8.62 \mathrm{~kJ} \mathrm{~mol}^{-1}\right)$ and smallest for Ac $\left(5.52 \mathrm{~kJ} \mathrm{~mol}^{-1}\right)$ with an overall trend of $\mathrm{Pa}>\mathrm{Th}>\mathrm{U}>$ Ac. This is the same trend as $V_{\mathrm{xc}}$, further demonstrating the reliability of the IQA method. The strengthening of the $\mathrm{An}^{3+}-\mathrm{He}$ bond with the inclusion of MP2-level correlation is reminiscent of the increase in the closed-shell metallophilic interaction in $\left[\mathrm{Cl}-\mathrm{M}-\mathrm{PH}_{3}\right]_{2}(\mathrm{M}=\mathrm{Cu}$, $\mathrm{Ag}, \mathrm{Au}, \mathrm{Rg}$ ) from HF to MP2. ${ }^{51}$

3.2.5 $\mathrm{Ac}^{3+}-\mathrm{Ng}(\mathrm{Ng}=\mathrm{Ne}-\mathrm{Xe})$ complexes. To investigate the influence of noble gas species on the structure and bonding of $\mathrm{AcNg}_{n}{ }^{q+}$ complexes, we extended our work to the heavier noble gas elements Ne-Xe. DFT search for the highest $\mathrm{CN}$ of $\mathrm{AcNg}_{n}{ }^{3+}$ $(\mathrm{Ng}=\mathrm{Ne}-\mathrm{Xe})$ complexes resulted in an $n$ of $15,10,10$, and 8 for $\mathrm{Ng}=\mathrm{Ne}, \mathrm{Ar}, \mathrm{Kr}$, and Xe, respectively, with the structures shown in Fig. 10. The highest $\mathrm{CN}$ reduces down the $\mathrm{Ng}$ group, which is not unexpected considering the increasing atomic radii of the $\mathrm{Ng}$ elements. The highest $\mathrm{CNs}$ of $\mathrm{Ac}^{3+}-\mathrm{Ar}$ and $\mathrm{Ac}^{3+}-\mathrm{Kr}$ are both 10 , with similar structure, and the average metal-ligand distance of the latter $(3.383 \AA)$ is larger than the former $(3.173 \AA)$. AIMD calculations were performed to confirm the thermodynamic stability of these structures (Fig. S7, ESI $\dagger$ ), and all of them remain as the potential energy minimum during the whole relaxation time at $10 \mathrm{~K}$.

During the AIMD relaxations, an interesting effect was discovered. It is logical that, for a compound consisting of $n$ $\mathrm{Ng}$ atoms and an An ion, if $n$ is larger than the highest $\mathrm{CN}$, the system will have the highest-coordinated geometry with the remaining $\mathrm{Ng}$ atoms accommodated in the second shell. If $n$ is less than the highest $\mathrm{CN}$, an $n$-coordinated structure is expected. But this is not true for $\mathrm{AcAr}_{12}{ }^{3+}(\mathrm{Ng}=\mathrm{Ar}-\mathrm{Xe})$. The optimized structures of $\operatorname{AcAr}_{n}^{3+}(n=10-12,14)$ are shown in Fig. 11. It can be seen that for $n=10,11$ and 14, 10-coordinated structures with the remaining Ar atoms in the second shell are obtained after AIMD relaxation at $T=10 \mathrm{~K}$. For $n=12$, however, the minimum potential energy structure is the icosahedral 12-coordinated one, which is stable even at $T=100 \mathrm{~K}$ (as shown in Fig. S8, ESI $\dagger$ ). The 10-coordinated structure with 2 more Ar atoms in the second shell was also obtained, but its energy is $11.64 \mathrm{~kJ} \mathrm{~mol}^{-1}$ higher than that of $\mathrm{AcAr}_{12}{ }^{3+}$. This 12-coordinated structure is also located for $\mathrm{Kr}$ and Xe.

To further study these $\mathrm{AcNg}_{12}{ }^{3+}$ structures, QTAIM analysis was conducted, with the results being presented in Table 6 . QTAIM analysis of the actinide-free $\mathrm{Ng}_{12}$ clusters were also conducted (Table 6). BCPs are found between $\mathrm{Ac}^{3+}$ and $\mathrm{Ng}$ atoms $(\mathrm{Ng}=\mathrm{He}-\mathrm{Xe})$ in all $\mathrm{AcNg}_{12}{ }^{3+}$, confirming direct $\mathrm{Ac}^{3+}-\mathrm{Ng}$ bonding. For the $\mathrm{Ng}_{12}$ clusters, BCPs are present between neighbouring $\mathrm{Ng}$ atoms in all systems ( $\mathrm{Ng}=\mathrm{He}-\mathrm{Xe}) . \mathrm{In} \mathrm{AcHe}_{12}{ }^{3+}$ and $\mathrm{AcNe}_{12}{ }^{3+}$, the $\mathrm{Ng}-\mathrm{Ng}$ BCPs disappear, suggesting that the stability of these two complexes is mainly due to the interaction between Ac and $\mathrm{Ng}$. However, for $\mathrm{AcNg}_{12}{ }^{3+}(\mathrm{Ng}=\mathrm{Ar}-\mathrm{Xe}), \mathrm{BCPs}$ are retained between neighbouring $\mathrm{Ng}$ atoms, indicating that $\mathrm{Ng}-\mathrm{Ng}$ interactions also contribute to the stability of these structures. As shown in Table 6, the electron densities at these $\mathrm{Ng}-\mathrm{Ng}$ BCPs (Ar-Xe) are uniform down the group, even though the average $\mathrm{Ng}-\mathrm{Ng}$ distance increases from $3.44 \AA$ A for Ar to $4.09 \AA$ A for Xe. The delocalization indices also increase from Ar to Xe, indicating enhanced interaction between $\mathrm{Ng}$ and $\mathrm{Ng}$. Moreover, the $\mathrm{Ng}-\mathrm{Ng}$ BCP data in $\mathrm{AcNg}_{12}{ }^{3+}(\mathrm{Ng}=\mathrm{Ar}-\mathrm{Xe})$ are slightly larger than that in the bare $\mathrm{Ng}_{12}$. It seems that the $12 \mathrm{Ng}$ atoms in $\mathrm{AcNg}_{12}{ }^{3+}$

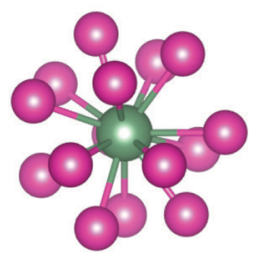

$\mathrm{AcNe}_{15}{ }^{3+}$

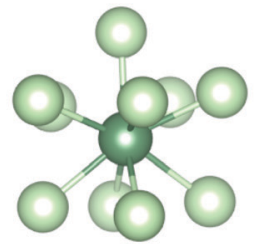

$\operatorname{AcAr}_{10}{ }^{3+}$

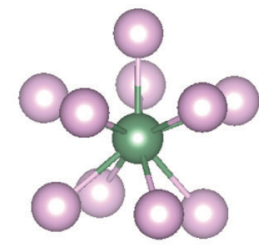

$\mathrm{AcKr}_{10}{ }^{3+}$

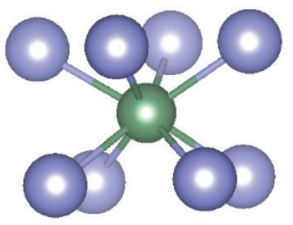

$\mathrm{AcXe}_{8}{ }^{3+}$

Fig. 10 Optimized highest $\mathrm{CN}$ structures of $\mathrm{Ac}^{3+}-\mathrm{Ng}$. 

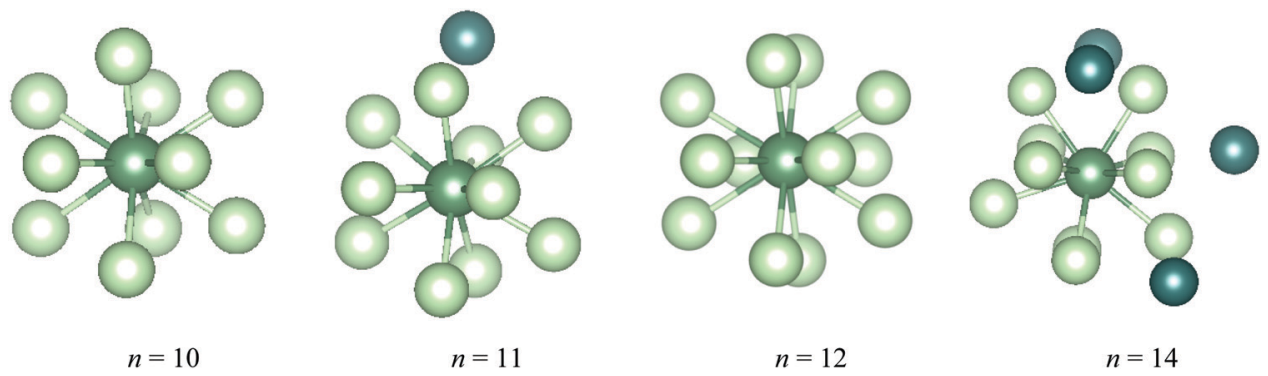

Fig. 11 The lowest potential energy structures of $\mathrm{AcAr}_{n}{ }^{3+}$ determined by AIMD at $T=10 \mathrm{~K}$. The Ar atoms in the second shell are highlighted in dark green.

Table 6 Structural, energetic, and QTAIM parameters (a.u.) for $\mathrm{Ac}-\mathrm{Ng}$ and $\mathrm{Ng}-\mathrm{Ng}$ BCPs in $\mathrm{AcNg}_{12}{ }^{3+}$ complexes. The QTAIM parameters for Ng-Ng BCPs in bare $\mathrm{Ng}_{12}$ are listed in parentheses

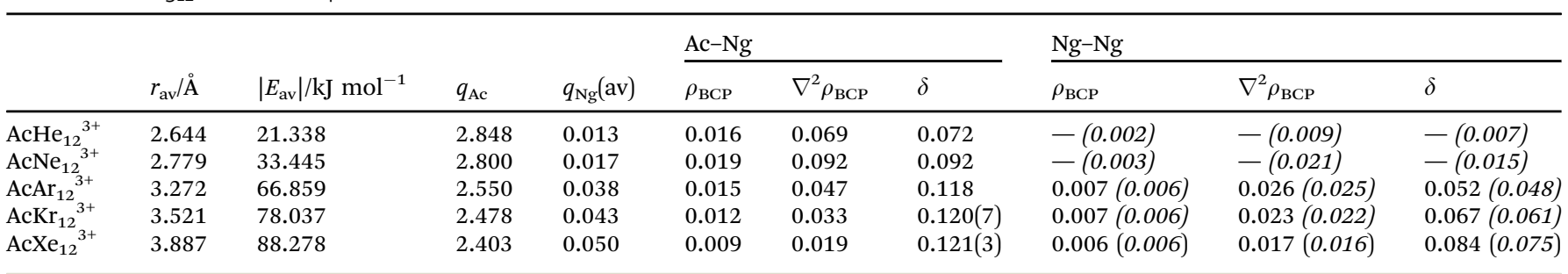

$(\mathrm{Ng}=\mathrm{Ar}-\mathrm{Xe})$ form a cage, trapping $\mathrm{Ac}^{3+}$ within and enhancing the binding strength of $\mathrm{Ng}_{12}$ in return. This phenomenon is also found in $\mathrm{ThNg}_{12}{ }^{4+}$ (geometrical and QTAIM parameters are listed in Table S3, ESI $\dagger$ ). In summary, we suggest that the highest CN for $\mathrm{AcNg}_{n}{ }^{3+}(\mathrm{Ng}=\mathrm{Ar}-\mathrm{Xe})$ is 12 considering the BCPs found between $\mathrm{Ac}^{3+}$ and all $\mathrm{Ng}$ atoms, although not all $\mathrm{AcNg}_{n}{ }^{3+}$ structures are stable from $n=1$ to 12 (e.g. $\mathrm{AcAr}_{11}{ }^{3+}, \mathrm{AcKr}_{11}{ }^{3+}$, $\left.\operatorname{AcXe}_{n}{ }^{3+}, n=9-11\right)$. The bonding situation in these complexes are similar to the $\mathrm{M}(\mathrm{EH})_{12}{ }^{19}$ which possess strong radial $\mathrm{M}-\mathrm{EH}$ bonding and weak peripheral E-E bonding.

The partial positive charge found on the $\mathrm{Ng}$ increases down the group (Table 6), with a corresponding decrease in $q_{\mathrm{Ac}}$, reflecting the increasing polarizability of the heavier $\mathrm{Ng}$ elements, and hence greater transfer of electrons from $\mathrm{Ng} \rightarrow$ Ac. The small values of $\rho_{\mathrm{BCP}}$ and $\delta$, as well as the positive $\nabla^{2} \rho_{\mathrm{BCP}}$, indicate the closed-shell nature of the $\mathrm{Ac}^{3+}-\mathrm{Ng}$ interaction. It is interesting to note that the $\mathrm{Ac}^{3+}-\mathrm{Ng} \rho_{\mathrm{BCP}}$ data increase from $\mathrm{He}$ to Ne before reducing in the heavier members of group 18. This is inconsistent with the metal-Ng interaction trend reported in previous theoretical work, which finds the largest BCP data at metal-Xe, ${ }^{52}$ but the difference in behaviour likely arises from the direct $\mathrm{Ng}-\mathrm{Ng}$ interaction in $\mathrm{AcNg}_{12}{ }^{3+}(\mathrm{Ng}=\mathrm{Ar}-\mathrm{Xe})$. The delocalization indices rise from He to Xe, although the change from Ar to Xe is quite small compared to the increase in binding energies, also due to the $\mathrm{Ng}-\mathrm{Ng}$ interaction.

The effect of outer coordination on the properties of $\mathrm{AcNg}_{12}{ }^{3+}$ are also studied. AIMD simulation of an $\mathrm{Ac}^{3+}-\mathrm{Ar}_{42}$ cluster clearly shows separate first, second and outer $\mathrm{Ar}$ atom shells (Fig. S9, ESI $\dagger$ ) with the former two containing 12 and $20 \mathrm{Ar}$ atoms, respectively. The structure of $\mathrm{Ac}^{3+}-\mathrm{Ar}$ with two $\mathrm{Ar}$ shells is shown in Fig. S10 (ESI $\dagger$ ). It can be seen that the second shell Ar has the same symmetry as that of the first shell. This structure is also located for $\mathrm{Ne}$ and $\mathrm{Kr}$. The structural and QTAIM parameters for these compounds are shown in Table S4 (ESI†). Comparison with Table 6 shows that the average Ac-Ng bond distance decreases slightly as the second shell is included. Moreover, the cluster size has no effect on the trend in $\mathrm{Ac}-\mathrm{Ng}$ and first shell $\mathrm{Ng}-\mathrm{Ng}$ BCP properties. It is worth noting there are very weak bonds between the $\mathrm{Ng}$ atoms in the second shell even though the distances are large (e.g. ca. $4 \AA$ for $\mathrm{Ar}$ ).

\section{Conclusions}

In this contribution, we have studied the geometric and electronic structures and bonding of a range of complexes involving early actinide ions and the noble gases. We began by identifying the most appropriate form of DFT to study these systems, benchmarking the $\mathrm{An}^{3+}$-He interaction energy curves against BSSE-corrected coupled cluster data, and concluding that dispersion-corrected BHLYP is a good choice for An = Ac-Pa and for U(VI), with B3LYP-D3 being better for U(III). Using this approach, we verified that $18 \mathrm{He}$ atoms can be accommodated in the primary coordination shell of $\mathrm{Ac}^{3+}$, and checked the stability of this system by AIMD. The very low incremental binding energy for the 18th He supports our conclusion that a coordination number of 18 is the maximum. We also report new 18-coordinate $\mathrm{Th}^{4+}-\mathrm{He}$ and $\mathrm{Th}^{3+}-\mathrm{He}$ complexes. The former is stable at $3 \mathrm{~K}$ by AIMD, but increasing the temperature to $10 \mathrm{~K}$ leads to one He migrating into the second coordination shell. In $\mathrm{ThHe}_{18}{ }^{3+}$, two of the He are $c a .0 .5 \AA$ further from the metal than 
the other 16, but QTAIM analysis supports the $\mathrm{CN}=18$ description. Further QTAIM and NPA of the 18 coordinated systems indicates closed shell bonding, supporting previous conclusions of charge-induced dipole interactions.

For $\mathrm{Pa}^{5+}-\mathrm{He}$ and $\mathrm{U}^{6+}-\mathrm{He}$ complexes, the highest $\mathrm{CN}$ is 17 , whereas for $\mathrm{Pa}^{3+}$ and $\mathrm{U}^{3+}$ it is 16. As expected, the average An-He binding energies in the 17 coordinate group valent species is significantly larger than in all four An(III) systems, and there is greater transfer of charge from $\mathrm{He} \rightarrow \mathrm{An}^{q^{+}}$in the more highly charged complexes. The average An-He binding energy correlates linearly with this charge transfer. The interatomic exchange-correlation energy $V_{\mathrm{xc}}$ determined by the IQA approach correlates linearly with the more widely used QTAIM delocalization index covalency metric, both indicating that An-He covalency increases from $\mathrm{AcHe}_{17}{ }^{3+}$ to $\mathrm{UHe}_{17}{ }^{6+}$. NPA of these $17 \mathrm{CN}$ systems shows that the $\mathrm{He} \rightarrow \mathrm{An}^{q+}$ charge transfer is primarily into metal $6 \mathrm{~d}$ orbitals for Ac, Th and Pa, but mainly into $5 \mathrm{f}$ for $\mathrm{U}$.

QTAIM analysis of the bonding in $\mathrm{AnHe}_{16}{ }^{3+}$ suggests chargeinduced interactions in all cases. HF and MP2 calculations on these systems indicate that the trend in correlation energy is $\mathrm{Pa}>\mathrm{Th}>\mathrm{U}>$ Ac; the same trend is seen in $V_{\mathrm{xc}}$.

Finally, we studied complexes of $\mathrm{Ac}^{3+}$ with the heavier noble gases. DFT searches show that the maximum coordination number decreases down the group, being 15, 10, 10 and 8 for $\mathrm{Ne}, \mathrm{Ar}, \mathrm{Kr}$ and Xe respectively. These complexes are confirmed as being stable at $10 \mathrm{~K}$ by AIMD. However, further AIMD analysis suggest that the highest coordination number for the $\mathrm{Ar}, \mathrm{Kr}$ and Xe systems is actually 12 as the $12 \mathrm{Ac}^{3+}-\mathrm{Ng}$ bond paths are confirmed by QTAIM. Comparison of the bonding in $\mathrm{AcNg}_{12}{ }^{3+}(\mathrm{Ng}=\mathrm{He}-\mathrm{Xe})$ using QTAIM shows enhanced $\mathrm{Ng} \rightarrow$ $\mathrm{Ac}^{3+}$ charge transfer as the $\mathrm{Ng}$ gets heavier, and the $\mathrm{Ac}-\mathrm{Ng}$ delocalization index increases.

\section{Conflicts of interest}

There are no conflicts to declare.

\section{Acknowledgements}

We are grateful to the China Scholarship Council and The University of Manchester for a PhD studentship for LY. We are also grateful to The University of Manchester for a PhD studentship to SC, and to its Computational Shared Facility and associated support services.

\section{References}

1 N. Bartlett, Proc. Chem. Soc., 1962, 218.

2 L. Belpassi, I. Infante, F. Tarantelli and L. Visscher, J. Am. Chem. Soc., 2008, 130, 1048-1060.

3 K. O. Christe, Angew. Chem., Int. Ed., 2001, 40, 1419-1421.

4 V. I. Feldman, F. F. Sukhov, A. Y. Orlov and I. V. Tyulpina, J. Am. Chem. Soc., 2003, 125, 4698-4699.
5 J. P. Wagner, D. C. McDonald, 2nd and M. A. Duncan, Angew. Chem., Int. Ed., 2018, 57, 5081-5085.

6 B. Liang, L. Andrews, J. Li and B. E. Bursten, J. Am. Chem. Soc., 2002, 124, 9016-9017.

7 I. Infante, L. Andrews, X. Wang and L. Gagliardi, Chem. Eur. J., 2010, 16, 12804-12807.

8 X. Wang, L. Andrews, J. Li and B. E. Bursten, Angew. Chem., Int. Ed., 2004, 43, 2554-2557.

9 S. Seidel and K. Seppelt, Science, 2000, 290, 117-118.

10 T. R. Galeev, C. Romanescu, W. L. Li, L. S. Wang and A. I. Boldyrev, Angew. Chem., Int. Ed., 2012, 51, 2101-2105.

11 D. Pollak, R. Goddard and K. R. Porschke, J. Am. Chem. Soc., 2016, 138, 9444-9451.

12 X. Gu, G. H. Chen, M. Ji, Y. X. Yao and X. G. Gong, Nanoscale, 2012, 4, 2567-2570.

13 I. A. Popov, T. Jian, G. V. Lopez, A. I. Boldyrev and L. S. Wang, Nat. Commun., 2015, 6, 8654.

14 A. Hermann, M. Lein and P. Schwerdtfeger, Angew. Chem., Int. Ed., 2007, 46, 2444-2447.

15 N. Kaltsoyannis, Angew. Chem., Int. Ed., 2017, 56, 7066-7069.

16 E. Ozama, S. Adachi, T. Takayanagi and M. Shiga, Chemistry, 2018, 24, 12716-12721.

17 M. Joshi and T. K. Ghanty, Chem. Commun., 2019, 55, 7788-7791.

18 S. X. Hu, P. Zhang, W. Zou and P. Zhang, Nanoscale, 2020, 12, 15054-15065.

19 M. von Hopffgarten and G. Frenking, J. Phys. Chem. A, 2011, 115, 12758-12768.

20 E. N. Esenturk, J. Fettinger, Y. F. Lam and B. Eichhorn, Angew. Chem., Int. Ed., 2004, 43, 2132-2134.

21 E. N. Esenturk, J. Fettinger and B. Eichhorn, J. Am. Chem. Soc., 2006, 128, 9178-9186.

22 S. Grimme, J. Antony, S. Ehrlich and H. Krieg, J. Chem. Phys., 2010, 132, 154104.

23 R. Ahlrichs, M. Bär, M. Häser, H. Horn and C. Kölmel, Chem. Phys. Lett., 1989, 162, 165-169.

24 W. Küchle, M. Dolg, H. Stoll and H. Preuss, J. Chem. Phys., 1994, 100, 7535-7542.

25 X. Cao, M. Dolg and H. Stoll, J. Chem. Phys., 2003, 118, 487-496.

26 X. Cao and M. Dolg, THEOCHEM, 2004, 673, 203-209.

27 C. Hättig, Phys. Chem. Chem. Phys., 2005, 7, 59-66.

28 A. Nicklass, M. Dolg, H. Stoll and H. Preuss, J. Chem. Phys., 1995, 102, 8942-8952.

29 B. P. Pritchard, D. Altarawy, B. Didier, T. D. Gibson and T. L. Windus, J. Chem. Inf. Model., 2019, 59, 4814-4820.

30 P. Deglmann, F. Furche and R. Ahlrichs, Chem. Phys. Lett., 2002, 362, 511-518.

31 M. J. Deegan and P. J. Knowles, Chem. Phys. Lett., 1994, 227, 321-326.

32 H.-J. Werner, P. J. Knowles, G. Knizia, F. R. Manby, M. Schutz, P. Celani, W. Gyorffy, D. Kats, T. Korona, R. Lindh, A. Mitrushenkov, G. Rauhut, K. R. Shamasundar, T. B. Adler, R. D. Amos, S. J. Bennie, A. Bernhardsson, A. Berning, D. L. Cooper, M. J. O. Deegan, A. J. Dobbyn, F. Eckert, E. Goll, C. Hampel, A. Hesselmann, G. Hetzer, T. Hrenar, 
G. Jansen, C. Koppl, S. J. R. Lee, Y. Liu, A. W. Lloyd, Q. Ma, R. A. Mata, A. J. May, S. J. McNicholas, W. Meyer, T. F. Miller III, M. E. Mura, A. Nicklass, D. P. O’Neill, P. Palmieri, D. Peng, K. Pfluger, R. Pitzer, M. Reiher, T. Shiozaki, H. Stoll, A. J. Stone, R. Tarroni, T. Thorsteinsson, M. Wang and M. Welborn, MOLPRO (Version 2019.2) a package of ab initio programs, 2019.

33 C. C. J. Roothaan, Rev. Mod. Phys., 1951, 23, 69.

34 M. J. Frisch, M. Head-Gordon and J. A. Pople, Chem. Phys. Lett., 1990, 166, 275-280.

35 M. J. Frisch, G. W. Trucks, H. B. Schlegel, G. E. Scuseria, M. A. Robb, J. R. Cheeseman, G. Scalmani, V. Barone, G. A. Petersson, H. Nakatsuji, X. Li, M. Caricato, A. V. Marenich, J. Bloino, B. G. Janesko, R. Gomperts, B. Mennucci, H. P. Hratchian, J. V. Ortiz, A. F. Izmaylov, J. L. Sonnenberg, D. Williams-Young, F. Ding, F. Lipparini, F. Egidi, J. Goings, B. Peng, A. Petrone, T. Henderson, D. Ranasinghe, V. G. Zakrzewski, J. Gao, N. Rega, G. Zheng, W. Liang, M. Hada, M. Ehara, K. Toyota, R. Fukuda, J. Hasegawa, M. Ishida, T. Nakajima, Y. Honda, O. Kitao, H. Nakai, T. Vreven, K. Throssell, J. A. Montgomery Jr., J. E. Peralta, F. Ogliaro, M. J. Bearpark, J. J. Heyd, E. N. Brothers, K. N. Kudin, V. N. Staroverov, T. A. Keith, R. Kobayashi, J. Normand, K. Raghavachari, A. P. Rendell, J. C. Burant, S. S. Iyengar, J. Tomasi, M. Cossi, J. M. Millam, M. Klene, C. Adamo, R. Cammi, J. W. Ochterski, R. L. Martin, K. Morokuma, O. Farkas, J. B. Foresman and D. J. Fox, Gaussian 16 (Version A. 03), Gaussian, Inc., Wallingford, CT, 2016.

36 S. F. Boys and F. Bernardi, Mol. Phys., 1970, 19, 553-566.

37 M. A. Blanco, A. Martin Pendas and E. Francisco, J. Chem. Theory Comput., 2005, 1, 1096-1109.

38 T. A. Keith, AIMAll (Version 19.10.12), TK Gristmill Software, Overland Park KS, USA, 2019.
39 A. D. Becke, J. Chem. Phys., 1993, 98, 1372-1377.

40 V. E. J. Berryman, J. J. Shephard, T. Ochiai, A. N. Price, P. L. Arnold, S. Parsons and N. Kaltsoyannis, Phys. Chem. Chem. Phys., 2020, 22, 16804-16812.

41 E. D. Glendening, J. K. Badenhoop, A. E. Reed, J. E. Carpenter, J. A. Bohmann, C. M. Morales, P. Karafiloglou, C. R. Landis and F. Weihold, NBO 7.0, Theoretical Chemistry Institute, University of Wisconsin, Madison, WI, 2018.

42 W. G. Hoover, Phys. Rev. A: At., Mol., Opt. Phys., 1985, 31, 1695-1697.

43 J. P. Perdew, K. Burke and M. Ernzerhof, Phys. Rev. Lett., 1996, 77, 3865.

44 R. F. W. Bader, Atoms in molecules: a quantum theory, Clarendon Press, Oxford, New York, 1990.

45 C. F. Matta and R. J. Boyd, in The Quantum Theory of Atoms in Molecules, ed. C. F. Matta and R. J. Boyd, Wiley-VCH Verlag GmbH \& Co. KGaA, Weinheim, 2007, vol. 1, pp. 1-34.

46 S. R. Daly, P. M. Piccoli, A. J. Schultz, T. K. Todorova, L. Gagliardi and G. S. Girolami, Angew. Chem., Int. Ed., 2010, 49, 3379-3381.

47 T. Arliguie, L. Belkhiri, S. E. Bouaoud, P. Thuery, C. Villiers, A. Boucekkine and M. Ephritikhine, Inorg. Chem., 2009, 48, 221-230.

48 J. A. Platts and R. J. Baker, Dalton Trans., 2020, 49, 1077-1088. 49 M. J. Tassell and N. Kaltsoyannis, Dalton Trans., 2010, 39, 6719-6725.

50 I. Kirker and N. Kaltsoyannis, Dalton Trans., 2011, 40, 124-131.

51 E. O'Grady and N. Kaltsoyannis, Phys. Chem. Chem. Phys., 2004, 6, 680-687.

52 W. Zou, D. Nori-Shargh and J. E. Boggs, J. Phys. Chem. A, 2013, 117, 207-212. 